\title{
CORROSION PROPAGATION PHASE AND BOND STRENGTH DEGRADATION OF REINFORCED CONCRETE STRUCTURES: STATE OF THE ART
}

\author{
NIROSHA D. ADASOORIYA, SAMINDI SAMARAKOON \& OVE TOBIAS GUDMESTAD \\ Department of Structural and Mechanical Engineering and Materials Science, \\ Faculty of Science and Technology, University of Stavanger, Norway.
}

\begin{abstract}
Corrosion causes damage to reinforcing steel in concrete structures and governs the service life of the structures. Currently, researchers are paying attention to modelling the behaviour of the bond between the concrete and steel interface of corroded reinforcement. The main objective of this paper is to study the recent research relevant to the bond behaviour at the interface between corroded ribbed bars and concrete and to identify the future research focus. Initially, the paper presents the mechanisms of corrosion damage of reinforced concrete by discussing corrosive agents, causes and effects. Then mechanisms of corrosion prorogation, mechanical properties of corroded reinforcing steel and effects of corrosion on bond degradation of reinforced concrete are discussed in details. Thereafter, recent experimental researches on bond degradation between reinforcement and concrete are reviewed. Previous studies have proposed formulae, which depend on cover, reinforcing bar diameter, concrete strength and corrosion level, to predict the ultimate bond strength. Effect of other parameters (i.e. type of the bars, bar spacing, crack size, aggregate size, type of loading, stress state and etc.) on bond strength have not been properly studied in literature. Bond strength against biaxial bending or combined load action has not been investigated. Finally, the paper concludes with the significance of testing naturally corroded test specimens, compared to the artificially corroded specimens, as well as discussing loading situations.

Keywords: bond degradation, corrosion, load capacity, reinforced concrete.
\end{abstract}

\section{INTRODUCTION}

The deterioration of concrete structures can be recognized in different ways, such as by corrosion of reinforcement, freeze-thaw damage, etc. The corrosion of reinforcing steel is a major durability issue of existing concrete structures. Generally, reinforcing steel and the surrounding concrete area are damaged by corrosion. Finally, it affects both the serviceability and load-carrying capacity of existing reinforced concrete structures $[1,2]$. Therefore, the understanding and modelling of reinforcing steel corrosion is very important when predicting the service life of reinforced concrete structures.

The reinforcing steel in concrete structures corrodes mainly due to carbonation, chloride ingression and any other chemical ingression. The deterioration process in reinforced concrete structures due to corrosion can be categorized into two phases, namely, initiation and propagation [3]. The initiation phase starts when chloride, carbonation or both begin to penetrate the concrete. The thin oxide layer formed on the surface of the embedded steel prevents from corrosion. The propagation phase starts by the passivation of the thin oxide layer on the surface of steel; this is the start of the active corrosion condition of the reinforcing steel. The corrosion of steel is getting in an active state when the $\mathrm{pH}$ value decreases. The summation of the time, from penetration until the threshold value is reached and the time from propagation until a maximum acceptable corrosion depth is reached, can be illustrated as the service life of the structure.

During the propagation phase of the corrosion, a reduction in the steel cross-sectional area, which affects both the ductility and the strength of the steel, and a volumetric expansion, 
which causes spalling of concrete and loss of bond strength in between the concrete and steel (due to both a weak interface layer and the disengagement of ribs), can be seen $[1,4]$. These effects may reduce the anchorage capacities and the composite interaction and change the geometric properties, due to a loss of the concrete cross section [5]. Finally, this causes changes in the overall stiffness of the structure, and a reduction in load carrying capacity can be observed. Several researchers have studied the relevant corrosion mechanisms and the corresponding structural behaviour of deteriorated reinforced concrete structures $[6,7]$. They pay significant attention to the accurate modelling of the bond strength and the corresponding mechanisms of corroded reinforced concrete structures.

The main objective of this paper is to review the recent research and findings related to bond strength degradation due to corrosion propagation in reinforcing steel, by considering the overall reasons for and causes and effects of corrosion. More specifically, the experimental research studies, relevant to the bond behaviour of corroded bars, are reviewed. Initially, the paper presents the mechanisms of corrosion prorogation and the effects of corrosion on bond degradation. Then recent experimental research on bond degradation between reinforcement and concrete is reviewed. Finally, taking into account notable issues and shortcomings in experimental research studies, a research gap has been identified in respect of modelling bond strength between corroded reinforcing steel and concrete.

\section{CORROSION DAMAGE OF REINFORCED CONCRETE STRUCTURES: CAUSES AND EFFECTS}

Chemicals, which are available in the environment or in the ingredients of concrete, are the main agents of the corrosion of reinforced concrete. Chloride in de-icing and seawater salts, carbonation and the reaction of sulphates with the tricalcium aluminate present in cement are some of the corrosive agents. The corrosion initiation phase starts when chloride, carbonation or both begin to penetrate the concrete [8]. The propagation phase starts when steel bars are active in corrosion.

During the propagation phase of the corrosion, the following can be observed: reduction of the cross-sectional area, loss of original shapes and disappearance of the reinforcement steel ribs [9-12]. This may also cause both a weak interface layer and finally the disengagement of the ribs $[9,13,14]$. The chemical reaction of the corrosion of steel bars produces rust materials, which expand the volume of the original steel. The previously mentioned loss of the steel bar section, volumetric expansion of the steel and a weak interfacial layer are the major causes of the deterioration of existing reinforced concrete structures.

The volumetric expansion places stresses on the concrete, leading to cracking [10]. This may finally cause spalling of the concrete cover area. This damage may accelerate the corrosion rate. In addition, it reduces the concrete cross section and finally reduces the overall stiffness of the structure. The disengagement of ribs due to volumetric expansion, cover cracking caused by spalling, and the weak interfacial layer affect the bond strength/mechanism, which is source for the interaction between the steel reinforcement and the surrounding concrete [9]. Then the bond between the steel and concrete significantly reduces the anchorage capacity and composite action of the steel and concrete, as shown in Fig. 1. The loss of the steel bar section can occur from either localized pitting corrosion, due to chloride ingress, or general (uniform) corrosion, due to carbonation. This may reduce the mechanical properties of the reinforcement, such as ductility and strength. General corrosion also affects the bond mechanism between the steel and concrete, as shown in Fig. 1. Finally, changes in the mechanical properties of the steel, anchorage capacity, composite behaviour, as well as the 


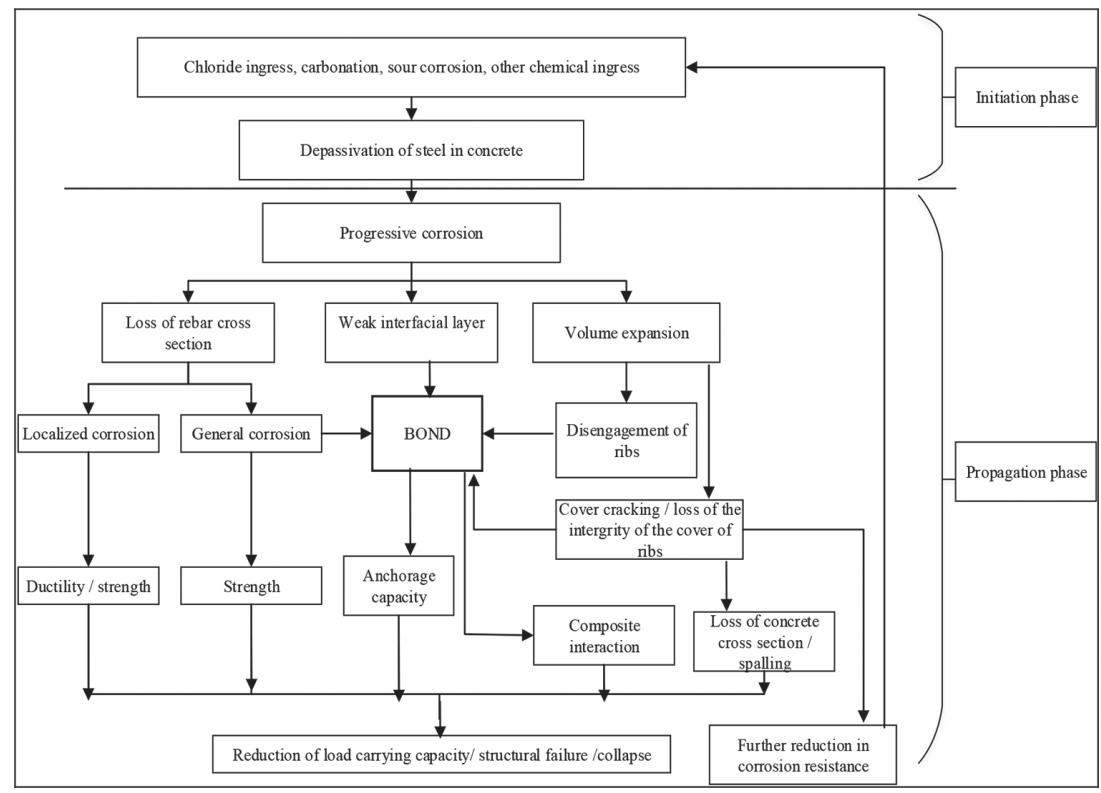

Figure 1: Fault tree for bond degradation and structural failure (adapted from $[9,16]$ )

loss of the concrete cross section, have the effect of reducing the load carrying capacity and ductility in the ultimate limit state, altering the overall stiffness and structural response of the reinforced concrete structures.

\section{MECHANISM OF CORROSION AND MECHANICAL PROPERTIES OF CORRODED STEEL BARS}

This section describes the chemical reaction involved in the corrosion of steel and the development of corrosion products. Changes to the mechanical properties of corroded reinforcing steel bars are briefly discussed in the latter part of the section.

\subsection{Chemical Process During Corrosion of Steel Bars}

The mechanism of corrosion in concrete can be described as follows: oxidation of iron takes places when the dissolution of iron produces ferrous iron $\left(\mathrm{Fe}^{2+}\right)$ at the anode with the presence of chloride or carbon dioxide. At the cathode, oxygen produces hydroxide irons $\left(\mathrm{OH}^{-}\right)$ which diffuses through the concrete. Then $\mathrm{OH}^{-}$and $\mathrm{Fe}^{2+}$ react and form ferrous hydroxide $\left(\mathrm{Fe}(\mathrm{OH})_{2}\right)$. Further oxidation of ferrous hydroxide produces the rust $\left(\mathrm{Fe}_{2} \mathrm{O}_{3} \cdot \mathrm{H}_{2} \mathrm{O}\right)$, as shown in Table 1) $[15,16]$. The resulting rust increases the volume of the steel, thus expanding the concrete. Moreover, the rust formation increases the volume to about six times that of steel about six times that of steel. It has very little positive effect on the onset of the corrosion but a negative effect afterwards on the service life of the structure, especially with regard to bond strength. Finally, concrete cracking and spalling can be seen due to corrosion of the steel in concrete. This causes a reduction in the cross-sectional area, which affects the cross-sectional properties. This may cause the overall stiffness of the structure and the structural response (i.e. stress, displacement, dynamic characteristics, etc.) to change. 


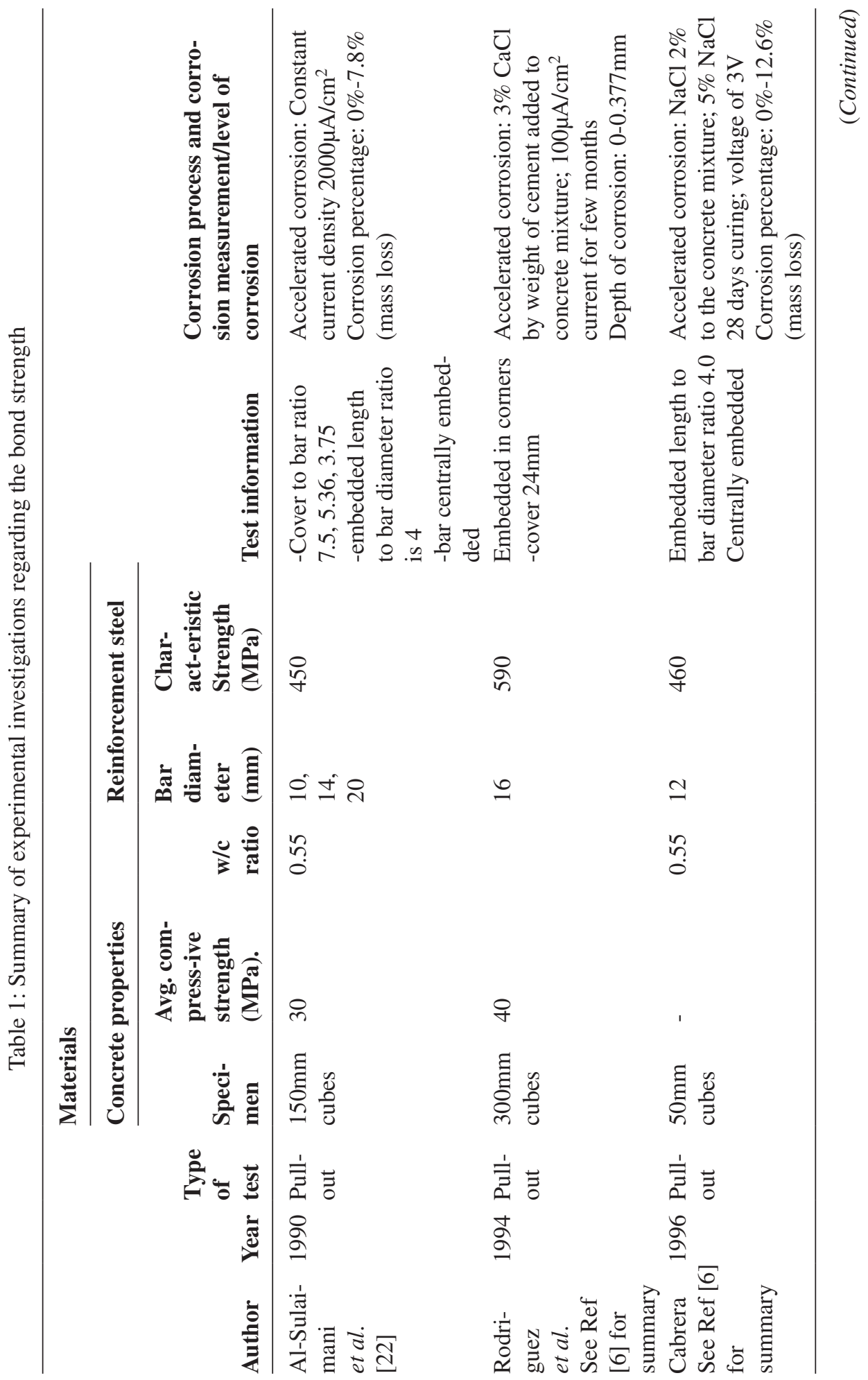




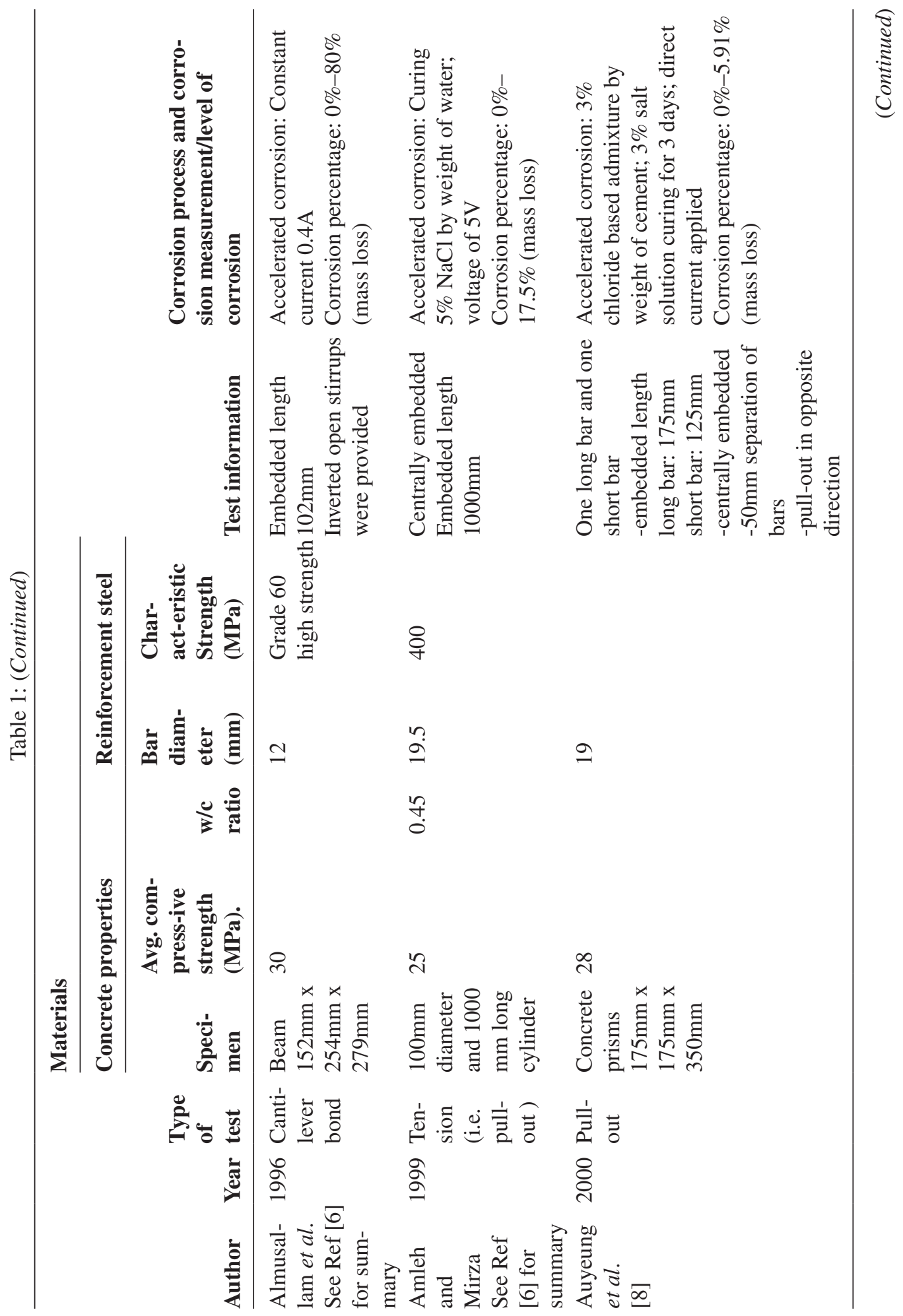




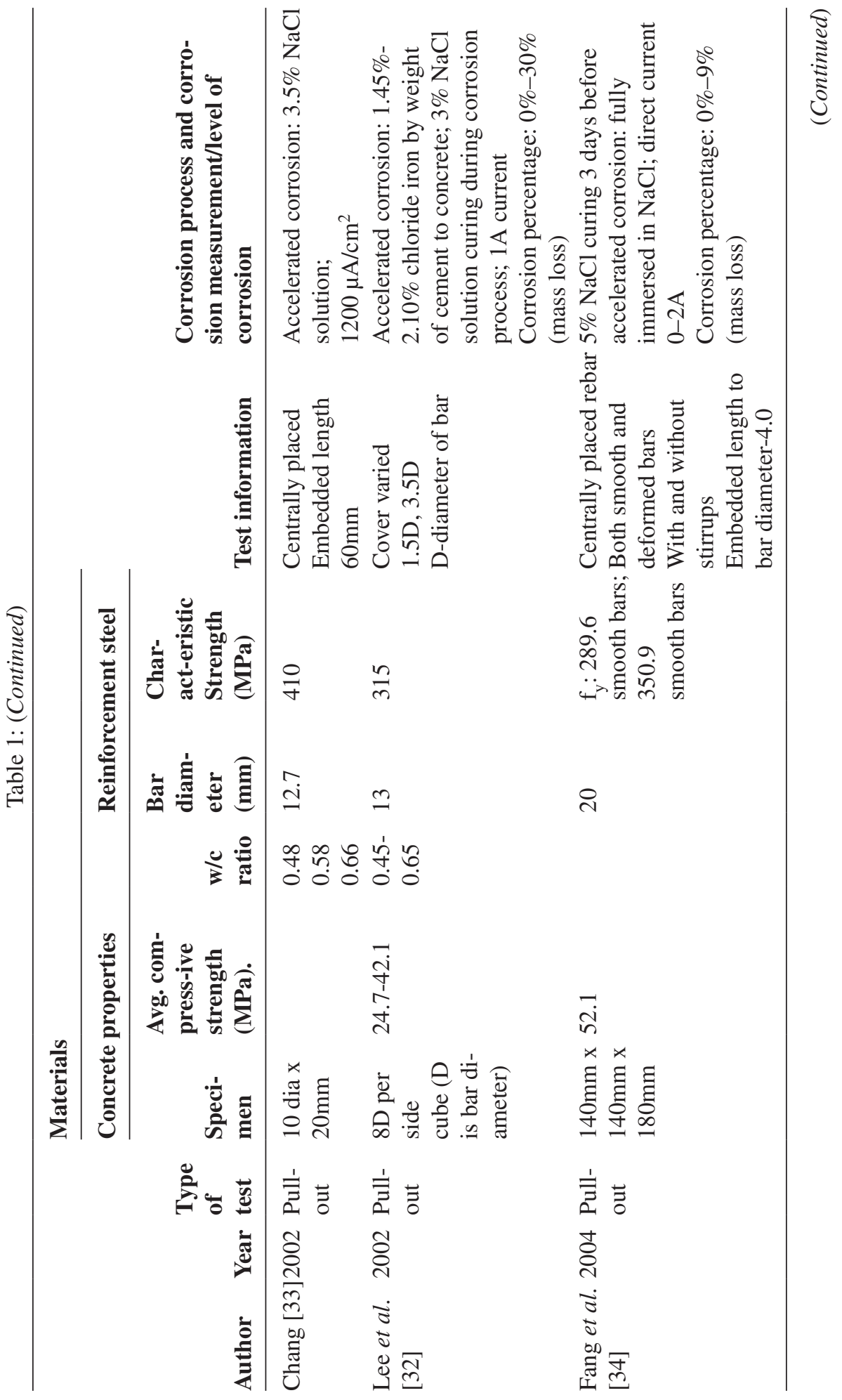




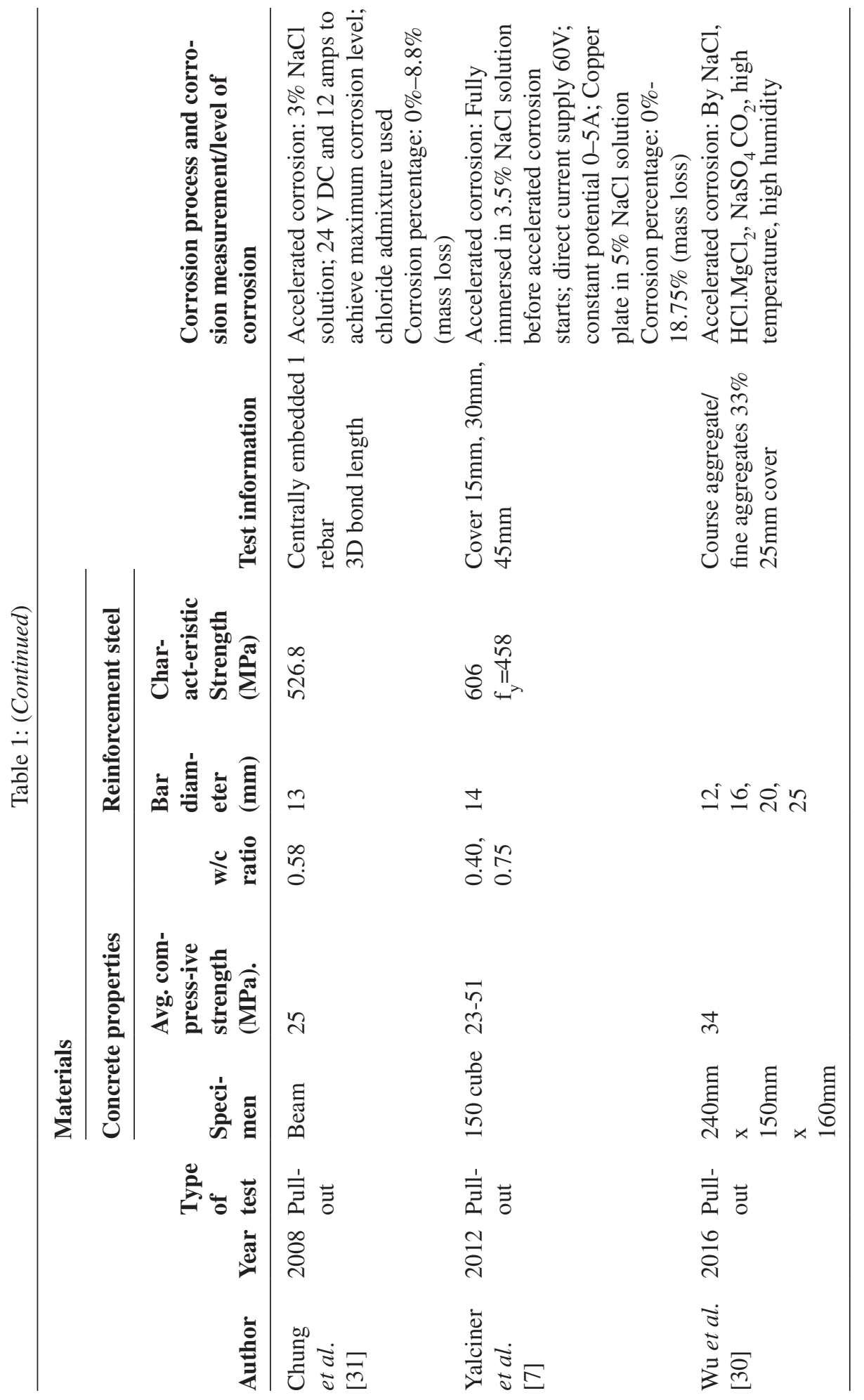




\subsection{Mechanical Properties of Corroded Steel Bars}

The corrosion of reinforcing steel bars can be categorized into two types named general corrosion and localized corrosion. Uniform corrosion is most commonly caused by carbonation whereas chloride ingress is the most common cause of pitting corrosion [9, 17, 18]. Both pitting and general corrosion degrade the mechanical properties of reinforcing steel bars [19].

In the presence of corrosion, usually in the pits, hydrogen-assisted stress-corrosion cracking can be seen (i.e. hydrogen embrittlement). The ultimate strain, therefore, is severely reduced, and researchers found that ductility may be reduced below the minimum required level specified by the design codes, as a result of around $10 \%$ of localized corrosion of the reinforcing steel bars [11]. The yield and ultimate strength are also significantly reduced by the effect of corrosion $[11,12,19,20]$. The localized pit develops locations of stress concentration and may be subject to local bending on the pitted cross section, due to the displacement of the centroid of the remaining cross section of the steel bar [9, 20].

\section{BOND STRENGTH BETWEEN REINFORCING STEEL AND CONCRETE}

The flexural strength of reinforced concrete members relies on the transfer of tensile forces known as bond, between the longitudinal reinforcement and concrete. The bond between concrete and steel reinforcement provides better composite action in reinforced concrete structures [10]. The bond consists of three main mechanisms: chemical adhesion, friction and mechanical interlock between concrete and steel. Bond stress can be defined as the shear stress between the steel and the concrete interface [10]. The bond stress initially develops due to the chemical bonds between the steel and the concrete in the low stress ranges. Micro cracks in the radial direction originate after the loss of the chemical bond. Slipping of the reinforcement bar may occur when increasing stress is acting on the steel bar. In this case, the friction, especially in plain bars, governs the bond strength. For ribbed bars, the bond strength is governed by the interaction of both friction and mechanical interlocking between the ribs of steel and the concrete. The bond strength depends on the grade of concrete, type and size of the main reinforcement bars, concrete cover and amount of transverse reinforcement [18].

When the bond degrades because of corrosion of the reinforcing steel, the cohesion, due to the chemical bond and the mechanical interlock between the ribs of steel and the concrete weakens. This may cause a loss of bond strength, although the corrosion products increase the bond strength slightly at the beginning, by stressing the interlock between the steel and concrete $[21,22]$. The bond strength drastically decreases with the increase in corrosion level, due to longitudinal and transverse cracks. The factors affecting the bond strength of corroded reinforced concrete structures are as follows: concrete grade, concrete cover, size and type of steel bar, confinement provided by transverse reinforcement, corrosion level and loading state/actual structural behaviour. The bond failure modes are generally recognized as splitting failure, pull-out failure and combined modes of failure [23]. Splitting occurs when transverse cracks lengthen to join up with cracks appearing from outside. Pull-out failure occurs when shear resistance (i.e. bond strength) exceeds the external force (i.e. when the load transfer mechanism fails).

\section{MODELS FOR BOND DEGRADATION BETWEEN REINFORCEMENT AND CONCRETE}

This section, which includes the models, describes the bond strength, bond stress-slip behaviour of corroded reinforced concrete members and the associated investigations. Initially, 
different bond strength modelling approaches are briefly discussed. Then the recent experimental research on bond degradation between reinforcement and concrete is reviewed. Recently proposed, widely applicable bond strength models and bond-slip behaviour are summarized at the end of this section.

\subsection{Bond Strength Modelling Approaches}

The available models for bond degradation can be categorized as analytical, numerical and experimental/empirical models. Analytical modelling and numerical modelling have been developed using bond stress-slip theories and finite element approaches [24-27]. Empirical modelling based on experimental investigations has been found to be more realistic and versatile for bond strength degradation. The widely used tests to evaluate bond strength include both concentric and eccentric pull-out test and bond beam test (i.e. standard beam or cantilever). The RILEM Recommendations for the testing and use of constructions materials [28] is the testing standard used for pull-out tests. These tests simply can be divided into two categories, namely, pull-out tests and flexural tests. All the tests had prepared control specimens to determine the bond strength of the non-corroded bar. The tests were carried out with and without stirrups. These experimental studies are utilized to understand bond stress-slip behaviour and to develop empirical bond strength models [28, 29]. Therefore, previous experimental research studies have been critically reviewed and summarized in the following subsections.

\subsection{Accelerated Corrosion Process/Artificial Corrosion Process}

It is also important to discuss the corrosion process when the experimental research of reinforced concrete specimens is concerned. It is noted that mainly accelerated corrosion [7, 30-34] has been widely used for previous research purposes by different researchers, although it does not give the fully real behaviour, compared to natural corrosion. The current density applied to accelerated corrosion tests may significantly affect the bond strength [9]. The chemical composition of corrosion products and its escape or penetrate behaviour are the main reasons for above differences. A few studies have been performed to obtain a relation between both accelerated corrosion and natural corrosion [2]. In summary, the acceleration of the corrosion of steel reinforcement has been brought about by an electrochemical method. To that end, concrete specimens were immersed in a sodium chloride solution to provide a chloride environment and current was provided to start and accelerate the electrochemical process. The percentage of sodium chloride has been decided on being as close to the chloride content available in the air or in a marine environment (i.e. generally 3\%-5\%), to find the most realistic environmental condition, according to the requirement.

This process can be established by many methods, for instance, by full or partial immersion in salt water or by both sodium chloride being added to the concrete mixture and then samples being immersed in sodium chloride liquid, in order to accelerate the corrosion process in both ways [7]. The direct current or voltage used to accelerate the process is decided by considering the value closest to the natural corrosion process.

\subsection{Experimental Investigations of Bond Strength by Pull-Out Tests}

Previous experimental investigations regarding bond degradation are briefly summarized, as shown in Table 1. The table shows that how researchers have used pull-out tests to model the 
bond strength by considering different parameters such as reinforcement with different diameters, with different rib patterns or without ribs and with different levels of strength. In addition, the diameter of the bar or the type, concrete compressive strength, concrete mix design or water-to-cement ratio are parameters considered for concrete [28]. Al-Sulaimani et al. [22] conducted a concentric pull-out test, as shown in Table 1, and ultimate bond strengths were presented as a function of percentage of corrosion. Bhargava et al. [6] presented average and standard deviations of bond strengths for different depths of corrosion (i.e. corrosion levels). Cabrera [6] also conducted a concentric pull-out test, as shown in Table 1, and bond strengths were presented as a function of percentage of corrosion, as in the work of Al-Sulaimani et al. [22]. The differences between these two experimental investigations are the reinforcement bar diameter, characteristic yield strength of the bar and the concrete grade. However, it is not possible to find a generalized relation (i.e. widely applicable) for bond strength, based only on the above tests, and therefore researchers have been motivated to perform further experimental studies. Almusallam et al. [29] conducted a bond strength test by using cantilever beams, as shown in Table 1, and ultimate bond strengths were presented as a function of degree/percentage of corrosion. The test represents a severe corrosion level. Amleh and Mirza [6] also performed a tension test on a concrete specimen of $100 \mathrm{~mm}$ diameter and $1 \mathrm{~m}$ length. The test was a concentric pull-out test, as shown in Table 1. Auyeung et al. [8] tests were conducted on concrete prisms, which were pulled out in opposite directions, with one long and one short bar at $50 \mathrm{~mm}$ spacing, as summarized in Table 1 . Finally, the normalized bond strengths versus percentage mass losses were presented. In 2002, the maximum bond strengths were obtained as a function of the degree of corrosion and the grade of the concrete by Lee et al. [32]. Fang et al. [34] conducted a concentric pull-out test for a higher grade of concrete, as shown in Table 1, and the bond strengths were discussed as a function of the degree of corrosion for both smooth and deformed bars, in cases with and without stirrups. Chung et al. [31] experimentally investigated bond degradation by using two types of bar pull-out tests with prismatic concrete specimens. The first specimen type consisted of reinforcing bars, which were pre-corroded before casting. The reinforcing bar of the second type of specimen was corroded after the concrete casting. Based on the experimental data, a bond strength model was proposed as a function of the corrosion level. Yalciner et al. [7] found a valuable empirical model for bond strength as a function of concrete cover, strength and corrosion level, by conducting a series of pull-out tests, as shown in Table 1. The bond-slip relations were comprehensively investigated. In 2016, Wu et al. [30] proposed a simplified model for examining bond strength between the cracked concrete and heavily corroded deformed steel bars. The proposed model depends on the degree of corrosion, the compressive strength of concrete, the width of the cracks in the concrete and the friction factor between the deteriorated concrete and the corroded steel bars.

Reinforcing steel bar diameters, which were used for previous studies, vary from 10 to 25 $\mathrm{mm}$. Both smooth and ribbed reinforcing bars have been used and their ultimate strength varies from $350 \mathrm{MPa}$ to $606 \mathrm{MPa}$. This shows that effect of the chemical composition of steel reinforcement has been considered for the bond strength by previous studies. The average concrete compressive strength of tested specimens was in the range of $23 \mathrm{MPa}-52 \mathrm{MPa}$. The current densities used for the accelerated corrosion process were in the range from $100 \mu \mathrm{A} /$ $\mathrm{cm}^{2}$ to $2000 \mu \mathrm{A} / \mathrm{cm}^{2}$. The considered $\mathrm{NaCl}$ percentage varies from $2 \%$ to $5 \%$ and this is closer to the $\mathrm{NaCl}$ percentage, which is generally available in the environment. The calculated mass loss due to accelerated corrosion were in the range of $0 \%-18.5 \%$ for most of the tests except one test, which was in the range of $0 \%-80 \%$. 


\subsection{Experimental Investigations of Bond Strength by Flexural Tests}

Several researchers have also carried out experimental investigations of bond strength by means of flexural tests. Al-Sulaimani et al. [22] tested beams of $150 \mathrm{~mm} \times 150 \mathrm{~mm}$ in crosssection and $1000 \mathrm{~mm}$ in length. The reinforcement details are one bottom bar of $12 \mathrm{~mm}$, two top bars of $10 \mathrm{~mm}$ and $6 \mathrm{~mm}$ spacing, between stirrups at $50 \mathrm{~mm}$. A four-point bending test was conducted, and bond strength was presented as a function of percentage of corrosion. The bond breakdown strengths and the ultimate bond strength were comprehensively discussed. Bhargava et al. [6] performed flexural tests on one-way slab specimens of $350 \mathrm{~mm} \times 150 \mathrm{~mm}$ in cross-section and $1300 \mathrm{~mm}$ in length. A four-point loading system was utilized.

Normal and silica fume concrete were considered separately with $10 \mathrm{~mm}$ main reinforcement bars, spacing of $125 \mathrm{~mm}$ and $20 \mathrm{~mm}$ clear cover. The degree of corrosion was estimated by the mass loss of steel compared to the original mass of the bar; it varied from $0 \%$ to $20.7 \%$ during this series of the tests. Normalized bond strengths were presented as a function of percentage mass loss due to corrosion. Chung et al. [31] tested slabs of $500 \mathrm{~mm} \times 90 \mathrm{~mm}$ in cross-section and $1000 \mathrm{~mm}$ in length. The slabs were reinforced with five $10 \mathrm{~mm}$ steel bars with $100 \mathrm{~mm}$ spacing, and the cover was $20 \mathrm{~mm}$. The slabs were tested by four-point loadings, and the concrete was subjected to bending failure. The degree of corrosion varied from $0 \%$ for the control specimens to $15 \%$ for the other specimens. The bond strength was presented as a function of the percentage corrosion. The accelerated corrosion process was used for all the above flexural specimens, which were investigated by the previous researchers. However, researchers have recognized that the effect of natural behaviour differs from that of artificially corroded specimens (i.e. natural corrosion may affect structural behaviour in a different way from that of artificially corroded members) [9]. To overcome this problem to some extent, Tahershamsi et al. [9] carried out an investigation of the bond capacity of naturally corroded reinforcements. Beam specimens were extracted from a 32-year-old bridge and were tested by four-point loadings. Both gravimetric measurements and advanced 3D optical scanning were used to measure the degree of corrosion. The relation between degree of corrosion, splitting crack widths and bond strength was investigated, and the results were compared with accelerated corrosion tests. The comparison reveals that naturally corroded tests provide higher bond strength than the artificially corroded specimens. This study provides a platform for understanding the structural behaviour of existing structures due to the effects of naturally corroded reinforcements.

\subsection{Bond Strength Models and Bond Stress-Slip Relationships}

Following a review of previous experimental bond strength investigations in Sections 5.3 and 5.4 , it has been recognized that differences between the proposed bond strength relations may be due to various factors. These are such as: (1) the characteristic strength of the steel bars; (2) the difference in material properties of concrete due to different mix proportions or production processes (i.e. compaction and curing); (3) uneven salt solution; (4) corrosion process, natural or artificial, etc. However, this section summarizes a widely used mass loss relation to determine the degree of corrosion/corrosion level, a recently proposed realistic empirical bond strength model and bond-slip relationship.

The theoretical mass loss due to corrosion $\left(m_{t}\right)$ can be calculated by Faraday's law $[1,7]$ as shown below: 


$$
m_{t}=\frac{t \times I \times M}{z \times F}
$$

where $I$ is the current; $M$ is the molar mass of iron, which is taken as $55.847 \mathrm{~g} / \mathrm{mol} ; z$ is the valency of the element, which is taken as two for steel; $t$ is time; and $F$ is the Faraday's constant, which is taken as 96,487 coulombs. The actual mass loss $\left(m_{a}\right)$ due to the corrosion can be approximately obtained as [7]:

$$
m_{a}=0.703 \times m_{t}-1.5(\mathrm{gr})
$$

The corrosion level or percentage of actual mass loss $\left(C_{L}\right)$ can be calculated by obtaining percentage ratio of the difference between the initial and final weights of the steel as

$$
C_{L}=\left(\frac{m_{a}}{m_{i}}\right) \times 100 \%
$$

where $m_{i}$ is the initial mass of the reinforcement bars before corrosion,

The ultimate bond strength $\left(\tau_{b u}\right)$ of uncorroded specimens is given as a function of concrete cover and strength, as shown below [7]

$$
\tau_{b u}=-2.7143+0.362 f_{c}^{\prime}+2.3296\left(\frac{c_{n o m}}{D}\right)(\mathrm{MPa})
$$

where $c_{\text {nom }} / D$ is the nominal cover to bar diameter ratio and $f_{c}$ is the strength of the concrete. Three separate empirical relations have been proposed [7] to predict precisely the ultimate bond strength of corroded members, based on the $c_{\text {nom }} / D$ ratios and corrosion levels.

$$
\begin{gathered}
\text { If } \frac{c_{n o m}}{D}<2 a \operatorname{and}_{\substack{0 \leq C_{L} \leq 4 \text { for } f_{c}^{\prime}=23 \mathrm{MPa} \\
0 C_{L} \leq 0.8 \text { for } f_{c}^{\prime}=51 \mathrm{MPa}}} \\
\tau_{b u}=-0.40551 f_{c}^{\prime}-0.25306\left(\frac{c_{\text {nom }}}{D}\right)+0.97926 C_{L}(\mathrm{MPa}) \\
\text { If } \frac{c_{\text {nom }}}{D} \geq 2 \operatorname{and}_{\substack{0 \leq C_{L} \leq 1.4 \text { for } f_{c}^{\prime}=23 \mathrm{MPa} \\
0 \leq C_{L} \leq 0.68 \text { for } f_{c}^{\prime}=51 \mathrm{MPa}}} \\
\tau_{b u}=e^{\left(-0.01572 f_{c}^{\prime}+0.22957\left(\frac{c_{\text {nom }}}{D}\right)+0.13946 C_{L}+1.75913\right)}(\mathrm{MPa})
\end{gathered}
$$

If the corrosion levels are different from the limits given in the above relations and if $1 \leq \frac{c_{n o m}}{D} \leq 3.2$ then:

$$
\tau_{b u}=e^{\left(-0.01667 f_{c}^{\prime}-1.06499 W_{c r}+0.20658\left(\frac{c_{n o m}}{D}\right)-0.12928 C_{L}+1.80139\right)}(\mathrm{MPa})
$$

where $W_{c r}$ is the crack width. This research investigation shows the possibility of predicting empirical relations for bond strength as a function of crack width and corrosion levels for different $c_{\text {nom }} / D$ ratios and concrete strengths.

The bond-slip behavior was also investigated experimentally in 2012 [7]. The slip of uncorroded reinforcement bars was decreased by increasing the cover to bar diameter ratio ( $c_{\text {nom }} / D$ ratio) and 
the compressive strength of the concrete. The slip was found to be less for lower concrete grades at lowest $c_{\text {nom }} / D$ ratio for corroded reinforcement bars. In addition, the slip decreased for higher concrete grades at the same corrosion level, when the $c_{\text {nom }} / D$ ratio was increased. The bond strength and bond-slip behaviour of corroded reinforcements with different concrete classes and $c_{\text {nom }} / D$ ratios may provide a better platform for structural performance evaluation of existing reinforced concrete structures.

\subsection{Discussion}

The previous experimental investigations demonstrate that there are several parameters (as shown in Table 2), which significantly affect the bond strength and bond-slip behaviour of reinforced concrete structures during the corrosion propagation phase.

The previous majority of experimental studies of bond strength degradation were mainly based on pull-out tests with different parameters. During the pull-out test, reinforcing steel is in tension and concrete is compressed and therefore concrete does not crack. However, during the flexural test both concrete and the reinforcement are in tension and hence concrete cracks. In this case, the concrete cracking results in-and-out-stress distribution of bond stress. Therefore, the pull-out test does not generally represent the real behavior of reinforced concrete under bending. Recently few experimental studies have been done under flexural behaviour with beams and one-way slabs (i.e. uniaxial bending nature). Bond strength against biaxial bending or combined action (i.e. load interaction) has not been examined. The bond strength has not been widely studied under other cyclic or impact loading situations. Moreover, most of the laboratory load testing have been carried out after corroding the reinforcement. However, in reality, corrosion starts while structural members withstanding loads. Therefore, it is vital to study the behavior of bond strength in such situations as well.

It has been recognized that the effect of natural behaviour differs from that of artificially corroded specimens (i.e. natural corrosion may affect structural behaviour in a different way

Table 2: Bond behaviour governing parameters

\begin{tabular}{ll}
\hline Classification & Parameters \\
\hline Reinforcement bar & $\begin{array}{l}\text { Plain or smooth bars, bar diameter, rib size and spacing, em- } \\
\text { bedded length, chemical composition }\end{array}$ \\
Concrete & $\begin{array}{l}\text { Strength class, w/c ratio, aggregate type, cement type, additives, } \\
\text { admixtures, permeability, porosity, concrete cover, crack size, } \\
\text { production process, electrical properties of the raw materials } \\
\text { Compression, tension, bending, combined action, static or } \\
\text { dynamic, impact, uniaxial or multiaxial, position of reinforce- } \\
\text { ment bars } \\
\text { Compression, tension, bending, combined action, static or } \\
\text { dynamic, impact, uniaxial or multiaxial, position of reinforce- } \\
\text { ment bars } \\
\text { Temperature, humidity level, Cl or CO2 availability in air } \\
\text { Environmental factors } \\
\text { Corrosion process }\end{array} \quad \begin{array}{l}\text { Artificial or natural, rate of corrosion, percentage of NaCl for } \\
\text { curing, percentage of NaCl in concrete mixture } \\
\text { Concrete structure }\end{array}$ \\
Size, functionality, loading state, loading history, age
\end{tabular}


from that of artificially corroded members). A proper correlation has not yet been identified between natural and artificial corrosion.

Gravimetric measurements have been widely used for determining the degree of corrosion of test specimens. Usage of this technique is difficult for existing structures. The corrosion propagation phase can be subdivided into stages with different corrosion levels, which can be measured with non-destructive measurements such as corrosion potential mapping, 3D optical scanning, etc. The application of these techniques is not widely reported in bond-strength degradation studies.

\section{CONCLUSIONS}

This paper has presented the mechanisms of corrosion propagation and the effects of corrosion on bond degradation of reinforced concrete structures. Previous experimental research into degradation of the bond between reinforcement and concrete has been reviewed, and a few recently proposed, widely applicable bond strength models and bond-slip relationships have been summarized. The parameters, which significantly affect the bond strength and bond-slip behaviour of reinforced concrete structures, have been listed. It is important to perform more experimental parametric studies to verify the simplified tests, which were used to provide empirical bond strength models for different loading situations. A proper correlation between natural and artificial corrosion should be proposed in future. More studies on role of confinement in bond degradation are recommended. It is very important that conclusions are drawn by repeating experimental investigations, which represent real behaviour, as concrete is a heterogeneous construction material. It is a matter of high importance and necessity to establish accurate propagation models, which can easily be applied by practising engineers.

\section{REFERENCES}

[1] Fang, C., Lundgren, K. \& Plos, M., Bond behaviour of corroded reinforcing steel bars in concrete. Cement and Concrete Research, 36(10), pp. 1931-1938, 2006. https://doi.org/10.1016/j.cemconres.2006.05.008

[2] Lundgren, K., Tahershamsi, M., Zandi, K. \& Plos, M., 1, Tests on anchorage of naturally corroded reinforcement in concrete. Materials and Structures, 48(7), pp. 20092022, 2014. https://doi.org/10.1617/s11527-014-0290-y

[3] Tutti, K., Corrosion of steel in concrete, Swedish Cement and Concrete Research Institute, 1982.

[4] Lundgren, K., Modelling the effect of corrosion on bond in reinforced concrete. Magazine of Concrete Research, 54(3), pp. 165-173, 2002. https://doi.org/10.1680/macr.54.3.165.38798

[5] Di Qiao, Experimental And Numerical Study On Corrosion-Induced Damages On Reinforced Concrete Structures, 2017. Available at: http://concrete-lab.civil.nagoya-u. ac.jp/homepage/j/2015-06-26\%20Qiao's\%20Thesis.pdf. (Accessed 17 February 2017).

[6] Bhargava, K., Ghosh, A.K., Mori, Y. \& Ramanujam, S., Corrosion-induced bond strength degradation in reinforced concrete-Analytical and empirical models. Nuclear Engineering and Design, 237(11), pp. 1140-1157, 2007.

https://doi.org/10.1016/j.nucengdes.2007.01.010 
[7] Yalciner H., Eren, O. \& Serhan, S., An experimental study on the bond strength between reinforcement bars and concrete as a function of concrete cover, strength and corrosion level. Cement and Concrete Research, 42(5), pp. 643-655, 2012.

https://doi.org/10.1016/j.cemconres.2012.01.003

[8] Auyeung, Y., Balaguru, P. \& Chung, L., Bond behavior of corroded reinforcement bars. ACI Structural Journal, 97(2), pp. 214-220, 2000. https://doi.org/10.14359/826

[9] Tahershamsi, M., Structural effects of reinforcement corrosion in concrete structures, $\mathrm{PhD}$ thesis, Chalmers University of Technology, Gothenburg, Sweden, 2016.

[10] Amleh, L. \& Ghosh, A., Modeling the effect of corrosion on bond strength at the steelconcrete interface with finite-element analysis. NRC Research Press Web Site, available at: http://www.nrcresearchpress.com/ (Accessed on 17 February, 2017).

[11] Du, Y.G., Clark L.A. \& Chan, A.H.C., Residual capacity of corroded reinforcing bars. Magazine of Concrete Research, 57(3), pp. 135-147, 2005. https://doi.org/10.1680/macr.57.3.135.60482

[12] Du, Y.G., Clark L.A. \& Chan, A.H.C., Effect of corrosion on ductility of reinforcing bars. Magazine of Concrete Research, 57(7), pp. 407-419, 2005. https://doi.org/10.1680/macr.2005.57.7.407

[13] Fanga, C., Lundgren, K., Chen, L. \& Zhu, C., Corrosion influence on bond in reinforced concrete. Cement and Concrete Research, 34(11), pp. 2159-2167, 2004. https://doi.org/10.1016/j.cemconres.2004.04.006

[14] Condition control and assessment of reinforced concrete structure exposed to corrosive environments, fib state of art report, May 2011.

[15] Markeset, G. \& Vennesland, Ø. (eds), Critical chloride content in reinforced concrete. SINTEF Building and Infrastructure COIN Workshop, 5-6 June 2008, Trondheim, Norway. COIN Project Report 6, 2008.

[16] Markeset, G. \& Myrdal, R., Modelling of reinforcement corrosion in concrete-state of the art - COIN project report 7. SINTEF Building and Infrastructure, 2008.

[17] Liu, T. \& Weyers, R.W., Modelling the dynamic corrosion process in chloride contaminated concrete structures. Cement and Concrete Research, 28(3), pp. 365-379, 1998. https://doi.org/10.1016/s0008-8846(98)00259-2

[18] Bond of Reinforcement in Concrete, fib Bulletin No. 10, State-of-art report, 2000.

[19] Apostolopoulos, C.A. \& Papadakis, V.G., Consequences of steel corrosion on the ductility properties of reinforcement bar. Construction and Building Materials, 22(12), pp. 2316-2324, 2008.

https://doi.org/10.1016/j.conbuildmat.2007.10.006

[20] Fernandez, I., Bairán, J.M. \& Marí, A.R., Corrosion effects on the mechanical properties of reinforcing steel bars. Fatigue and $\sigma-\varepsilon$ Behavior. Construction and Building Materials, 101, pp. 772-783, 2015.

https://doi.org/10.1016/j.conbuildmat.2015.10.139

[21] Elbusaefi, A.A., The effect of steel bar corrosion on the bond strength of concrete manufactured with cement replacement materials, $\mathrm{PhD}$ thesis, Cardiff University, 2014.

[22] Al-Sulaimani, G.J., Kaleemullah, M., Basunbul, I.A. \& Rasheeduzzafar, Influence of corrosion and cracking on bond behavior and strength of reinforced concrete members. International Concrete Abstracts Portal, 87(2), pp. 220-231, 1990.

https://doi.org/10.14359/2732 
[23] Lundgren K., Effect of corrosion on the bond between steel and concrete: an overview. Magazine of Concrete Research, 59(6), pp. 447-461, 2007.

https://doi.org/10.1680/macr.2007.59.6.447

[24] Fib CEB-FIP Model Code for Concrete Structures, 2010.

[25] Lundgren, K., Kettil, P., Hanjari, K.Z., Schlune, H. \& Roman, A.S., Analytical model for the bond-slip behavior of corroded ribbed reinforcement. Structure and Infrastructure Engineering, 8(2), pp.157-167, 2012.

https://doi.org/10.1080/15732470903446993

[26] Lundgren, K. \& Gylltoft, K., A model for the bond between concrete and reinforcement. Magazine of Concrete Research, 52(1), pp. 53-63, 2000.

https://doi.org/10.1680/macr.2000.52.1.53

[27] Jendele, L. \& Cervenka, J., Finite element modelling of reinforcement with bond. Computers and Structures, 84(28), pp. 1780-1791, 2006.

https://doi.org/10.1016/j.compstruc.2006.04.010

[28] RC 6 Bond Test for Reinforcement Steel. 2. Pull-out test, 1983, RILEM TC, Book title: RILEM Recommendations for the Testing and Use of Constructions Materials, RILEM, pp. 218-220, 1994.

[29] Almusallam, A.A., Al-Gahtani, A.S., Aziz, A.R. \& Rasheeduzzafar, Effect of reinforcement corrosion on bond strength. Construction and Building Materials, 10(2), pp. 123-129, 1996. https://doi.org/10.1016/0950-0618(95)00077-1

[30] Wu, Y.Z., Lv, H.L., Zhou, S.C. \& Fang, Z.N., Degradation model of bond performance between deteriorated concrete and corroded deformed steel bars. Construction and Building Materials, pp. 89-95, 2016.

https://doi.org/10.1016/j.conbuildmat.2016.04.061

[31] Chung, L., Jay Kim, J.H. \& Yi, S.T., Bond strength prediction for reinforced concrete members with highly corroded reinforcing bars. Cement and Concrete Composites, $\mathbf{3 0}$, pp. 603-611, 2008.

https://doi.org/10.1016/j.cemconcomp.2008.03.006

[32] Lee, H.S., Noguchi, T. \& Tomosawa, F., Evaluation of the bond properties between concrete and reinforcement as a function of the degree of reinforcement corrosion. Cement and Concrete Research, 32(8) pp. 1313-1318, 2002.

https://doi.org/10.1016/s0008-8846(02)00783-4

[33] Chang, J.J., A study of the bond degradation of rebar due to cathodic protection current. Cement and Concrete Research, 32, pp. 657-663, 2002. https://doi.org/10.1016/s0008-8846(01)00740-2

[34] Fang, C., Lundgren, K., Chen, L. \& Zhu, C., Corrosion influence on bond in reinforced concrete. Cement and Concrete Research, 34, pp. 2159-2167, 2004. https://doi.org/10.1016/j.cemconres.2004.04.006 